\title{
The Toronto General Hospital Transitional Pain Service: development and implementation of a multidisciplinary program to prevent chronic postsurgical pain
}

\author{
This article was published in the following Dove Press journal: \\ Journal of Pain Research \\ 12 October 2015 \\ Number of times this article has been viewed
}

\author{
Joel Katz ${ }^{1-3}$ \\ Aliza Weinrib ${ }^{1,2}$ \\ Samantha R Fashler ${ }^{2}$ \\ Rita Katznelzon ${ }^{1,3}$ \\ Bansi R Shah' \\ Salima SJ Ladak' \\ Jiao Jiang' \\ Qing $\mathrm{Li}^{\prime}$ \\ Kayla McMillan' \\ Daniel Santa Mina ${ }^{5,6}$ \\ Kirsten Wentlandt ${ }^{4,7}$ \\ Karen McRae ${ }^{1,3}$ \\ Diana Tamir ${ }^{1,3}$ \\ Sheldon Lyn ${ }^{1,3}$ \\ Marc de Perrot ${ }^{8}$ \\ Vivek Rao9 \\ David Grant ${ }^{10}$ \\ Graham Roche-Nagle" \\ Sean P Cleary ${ }^{12}$ \\ Stefan OP Hofer ${ }^{13}$ \\ Ralph Gilbert ${ }^{14}$ \\ Duminda Wijeysundera ${ }^{1,3}$ \\ Paul Ritvo ${ }^{15}$ \\ Tahir Janmohamed ${ }^{16}$ \\ Gerald O'Leary',3 \\ Hance Clarke ${ }^{1,3}$ \\ 'Department of Anesthesia and Pain Management, \\ Toronto General Hospital, University Health Network, \\ University of Toronto, ${ }^{2}$ Department of Psychology, York \\ University, ${ }^{3}$ Department of Anesthesia, University of \\ Toronto, ${ }^{4}$ Palliative Care, University Health Network, \\ University of Toronto, ${ }^{5}$ Princess Margaret Cancer \\ Centre, University Health Network, University of \\ Toronto, ${ }^{6}$ Faculty of Kinesiology and Physical Education, \\ University of Toronto, ${ }^{7}$ Department of Family and \\ Community Medicine, University of Toronto, ${ }^{8}$ Division \\ of Thoracic Surgery, Toronto General Hospital, \\ 'Division of Cardiovascular Surgery, Toronto General \\ Hospital, ${ }^{10}$ Multiorgan Transplant Program, Toronto \\ General Hospital, "Division of Vascular Surgery, \\ Toronto General Hospital, ${ }^{12}$ Division of General \\ Surgery, Toronto General Hospital, ${ }^{13}$ Division of \\ Plastic Surgery, Toronto General Hospital, ${ }^{14}$ Division \\ of Otolaryngology - Head and Neck Surgery Toronto \\ of Otolaryngology - Head and Neck Surgery, Toron \\ General Hospital, ${ }^{15}$ Department of Kinesiology and
Health Science, York University, ${ }^{16}$ ManagingLife, Toronto, \\ ON, Canada
}

Correspondence: Joel Katz; Hance Clarke Pain Research Unit, Department of Anesthesia and Pain Management, Toronto General Hospital, 200 Elizabeth St., 3 EB-3 17, Toronto, ON, M5G 2C4, Canada

Email jkatz@yorku.ca; hance.clarke@uhn.ca
Abstract: Chronic postsurgical pain (CPSP), an often unanticipated result of necessary and even life-saving procedures, develops in $5-10 \%$ of patients one-year after major surgery. Substantial advances have been made in identifying patients at elevated risk of developing CPSP based on perioperative pain, opioid use, and negative affect, including depression, anxiety, pain catastrophizing, and posttraumatic stress disorder-like symptoms. The Transitional Pain Service (TPS) at Toronto General Hospital (TGH) is the first to comprehensively address the problem of CPSP at three stages: 1) preoperatively, 2) postoperatively in hospital, and 3) postoperatively in an outpatient setting for up to 6 months after surgery. Patients at high risk for CPSP are identified early and offered coordinated and comprehensive care by the multidisciplinary team consisting of pain physicians, advanced practice nurses, psychologists, and physiotherapists. Access to expert intervention through the Transitional Pain Service bypasses typically long wait times for surgical patients to be referred and seen in chronic pain clinics. This affords the opportunity to impact patients' pain trajectories, preventing the transition from acute to chronic pain, and reducing suffering, disability, and health care costs. In this report, we describe the workings of the Transitional Pain Service at Toronto General Hospital, including the clinical algorithm used to identify patients, and clinical services offered to patients as they transition through the stages of surgical recovery. We describe the role of the psychological treatment, which draws on innovations in Acceptance and Commitment Therapy that allow for brief and effective behavioral interventions to be applied transdiagnostically and preventatively. Finally, we describe our vision for future growth.

Keywords: Transitional Pain Service, chronic postsurgical pain, transition to chronic pain, opioid use, multidisciplinary treatment

\section{Introduction}

Chronic pain is the silent epidemic of our times. ${ }^{1}$ The economic costs of chronic pain in the US are estimated to exceed the costs of heart disease, cancer and diabetes. ${ }^{2}$ Chronic postsurgical pain (CPSP) is a significant driver of this cost, with annual direct and indirect per patient estimates of US\$41,000. ${ }^{3}$ Given that the one-year incidence of moderateto-severe CPSP is between 5\% and 10\%, and that world-wide, more than 230 million people undergo major surgery every year, the global annual cost of new cases of CPSP is in the hundreds of billions of dollars. ${ }^{6}$ Equally concerning is the humanitarian cost of CPSP, which is all too frequently the unanticipated result of necessary and even lifesaving surgery. CPSP deprives the individual of vital energy and productivity and leads to many negative secondary, downstream effects.? 
The response to this costly tragedy has been unacceptably slow. ${ }^{4}$ For more than 20 years, we have made progress in managing acute postsurgical pain through new insights and novel findings in pre-emptive/preventive analgesia. ${ }^{4,89} \mathrm{In}$ contrast, breakthroughs have not been made in minimizing the transition to CPSP. In order to accomplish this goal, we need a multidisciplinary preventive approach that involves intensive, perioperative psychological, medical, physical therapy, and pharmacological management interventions aimed at preventing and treating the factors that increase the risk of CPSP and associated disability., ${ }^{4,10,11}$

In this paper, we briefly review the main risk factors for CPSP and then describe a novel multidisciplinary pain program, the Transitional Pain Service (TPS), which we have developed and implemented over the past year (since 2014). The TPS is designed specifically to identify patients at risk of CPSP, to intervene in a tailored and timely way medically, psychologically, and with complementary treatments to minimize the transition to chronicity, and to reduce reliance on opioid medications by focusing on treatment across the hospital-to-home trajectory. We anticipate the TPS will produce substantial savings, shorter hospital stays, earlier weaning from opioid analgesic medications, reduced emotional distress, improved quality of life, and reduced incidence and severity of CPSP and disability. Preliminary data already support some of these anticipated outcomes. ${ }^{10,11}$

\section{Risk factors for CPSP}

Over the past several years, substantial advances have been made in identifying risk factors for CPSP ${ }^{4,5,12-19}$ (Figure 1). Our data and that from other published literature clearly show the following factors reliably predict CPSP across a range of surgical procedures: perioperative pain (the presence and intensity of preoperative pain, high intensity acute postoperative pain), ${ }^{20-25}$ perioperative opioid use, ${ }^{20,26}$ preoperative negative affective states including posttraumatic stress disorder (PTSD)-like symptoms, ${ }^{27}$ depression, ${ }^{28,29}$ anxiety, ${ }^{18,28,30-32}$ and pain catastrophizing. ${ }^{12,17,32,33}$ The known psychological risk factors for CPSP (negative affect, catastrophizing) are also risk factors for intense, acute postoperative pain and high/ excessive use of opioid analgesics in the acute postoperative setting. ${ }^{34,35}$ Inadequately controlled acute pain and excessive

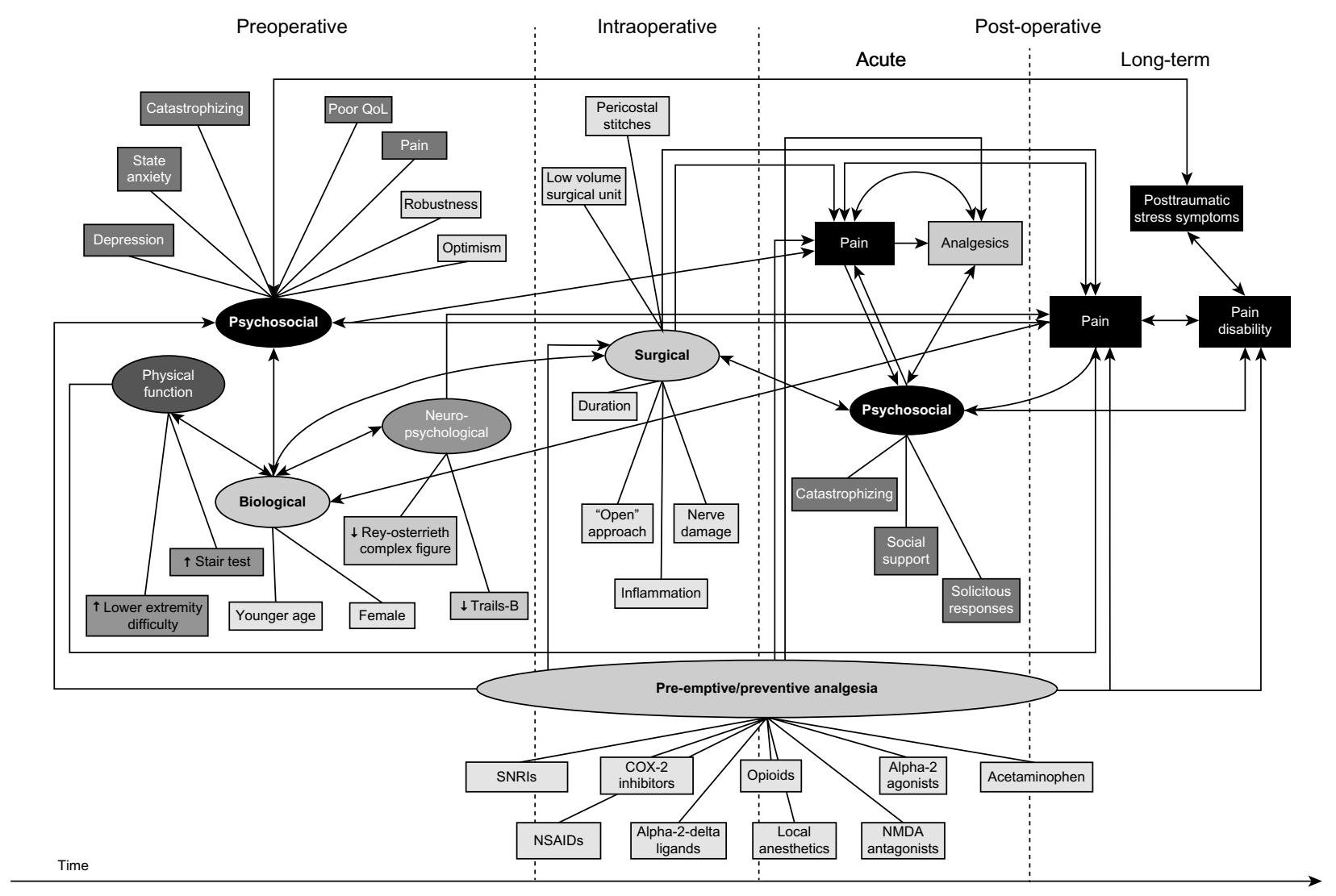

Figure I Schematic illustration of the processes involved in the development of chronic postsurgical pain and pain disability showing relationships among preoperative, intraoperative, and postoperative risk/protective factors. Copyright (c) 2009 Katz and Seltzer. Adapted with permission from Katz J, Seltzer Z. Transition from acute to chronic postsurgical pain: risk factors and protective factors. Expert Rev Neurother. 2009;9(5): 723-744. ${ }^{3}$

Abbreviations: QoL, quality of life; SNRIs, serotonin-norepinephrine reuptake inhibitors; NSAIDs, nonsteroidal anti-inflammatory drugs; NMDA, N-Methyl-D-aspartic acid. 
analgesic use have been repeatedly shown to delay recovery and hospital discharge following many surgeries. ${ }^{36-40}$ Moreover, high pain intensity, ${ }^{41,42}$ negative affect, ${ }^{41,43}$ and catastrophizing ${ }^{41,44}$ are all risk factors for opioid misuse/abuse in patients with chronic pain. Our own data show that 3\% of previously opioid-naïve patients continue to use opioids 90 days after major elective surgery. ${ }^{45}$ The TPS is designed to target and manage these known risks pre- and postsurgery in an effort to reduce pain, disability, and opioid misuse, while also benefitting the health care system by facilitating earlier discharge and reducing costs.

\section{Overview of the TPS}

The mission of the TPS is the treatment of patients who are at risk for transitioning from acute to CPSP. As such, it is the first service to comprehensively address the problem of CPSP after major surgery through multidisciplinary, coordinated care beginning preoperatively, extending postoperatively, and continuing into the posthospital discharge period once patients have returned home. The three primary goals of the TPS are to: 1) provide a novel, seamless approach to pre- and postoperative pain management for patients who are at increased risk for developing CPSP and pain disability, 2) manage opioid medication for medically complex patients post-discharge, and 3) improve patient coping and functioning in order to ensure as high a quality of life as possible after surgery.

\section{Institutional setting}

The TPS is situated at Toronto General Hospital (TGH), part of the University Health Network, in Toronto, ON, Canada. TGH is Canada's leading surgical center, specializing in surgical oncology, cardiac surgery, vascular surgery, and multiorgan transplantation, with more than 6,000 surgeries performed annually. TPS patients have undergone a variety of surgical procedures (Table 1) including procedures such as thoracotomy, mastectomy, and limb amputation, after which as many as one in two patients may develop CPSP. ${ }^{4,46}$

\section{TPS staff}

Presently, the TPS comprises five anesthesiologists with advanced training in acute and/or chronic interventional pain management, two clinical psychologists and trainees, three acute pain nurse practitioners, two physical therapists with expertise in acupuncture, a palliative care specialist/family physician, an exercise physiologist, a patient-care coordinator, and an administrative assistant.
Table I Table of surgical procedures for patients enrolled in the Transitional Pain Service

\begin{tabular}{|c|c|}
\hline Type of surgery & Specific surgeries \\
\hline \multicolumn{2}{|c|}{ Cancer-related surgeries } \\
\hline \multirow[t]{4}{*}{ Thoracic } & Lobectomy \\
\hline & Pneumonectomy \\
\hline & Wedge resection (lung) \\
\hline & Video-assisted thoracic surgery (VATS) \\
\hline \multirow[t]{9}{*}{ Gastrointestinal } & Esophagectomy \\
\hline & Whipple \\
\hline & Liver resection \\
\hline & Bowel resection \\
\hline & Bile duct reconstruction \\
\hline & Cholecystectomy \\
\hline & Colostomy \\
\hline & lleostomy \\
\hline & Gastrectomy \\
\hline Gynecologic oncology & $\begin{array}{l}\text { Total abdominal hysterectomy (with or } \\
\text { without bilateral salpingo-oophorectomy } \\
\text { and/or omentectomy) }\end{array}$ \\
\hline \multirow[t]{3}{*}{ Urologic } & Nephrectomy \\
\hline & Radical prostatectomy \\
\hline & Cystectomy \\
\hline \multirow[t]{5}{*}{ Head and neck } & Mandibulotomy \\
\hline & Maxillectomy \\
\hline & Glossectomy \\
\hline & Laryngectomy \\
\hline & Tracheostomy \\
\hline \multirow[t]{4}{*}{ Breast cancer } & $\begin{array}{l}\text { Total mastectomy (with deep inferior } \\
\text { epigastric artery perforator flap) }\end{array}$ \\
\hline & Modified radical mastectomy \\
\hline & Radical mastectomy \\
\hline & Breast reconstruction surgery \\
\hline \multirow[t]{4}{*}{ Cardiac surgeries } & Coronary artery bypass graft (CABG) \\
\hline & $\begin{array}{l}\text { Minimally invasive direct coronary artery } \\
\text { bypass (MIDCAB) }\end{array}$ \\
\hline & Heart valve surgery \\
\hline & Angioplasty \\
\hline \multirow[t]{6}{*}{ Vascular surgeries } & $\begin{array}{l}\text { Amputations (toe, below the knee, } \\
\text { above the knee) }\end{array}$ \\
\hline & Axillary-femoral bypass \\
\hline & Femoro-femoral bypass \\
\hline & Aortobifemoral bypass \\
\hline & Femoropopliteal bypass \\
\hline & Aortic aneurysm repair \\
\hline \multirow[t]{6}{*}{ Multiorgan transplant } & Kidney transplant \\
\hline & Kidney-pancreas transplant \\
\hline & Lung transplant \\
\hline & Liver transplant \\
\hline & Heart transplant \\
\hline & $\begin{array}{l}\text { Surgery for living donors (liver and } \\
\text { kidney) }\end{array}$ \\
\hline
\end{tabular}

\section{Patient flow during the pre- and intraoperative periods}

Patients are identified as candidates for the TPS as early as the surgical preadmission visit, when a comprehensive medical assessment is performed, covering key areas such 
as preexisting conditions, current medications, and special considerations for anesthesia. At this time, approximately $12.5 \%$ of patients are identified with a "pain alert" due to chronic pain problems requiring daily opioid medication. This "pain alert" is attached to their chart for the duration of their surgical admission. These patients are assessed after surgery by the TPS, with particular attention to their needs as "acuteon-chronic" pain patients with high opioid requirements.

For a subset of highly complex patients, a multidisciplinary perioperative pain management plan is created prior to surgery; for example, a personalized pain management plan was created for a patient who was awaiting lung transplant in hospital, due to his complex clinical picture, including chronic degenerative lung disease, chronic back pain with high daily opioid use, a history of misuse of street drugs, as well as depression and anxiety. After assessment by the TPS, his opioid medication was reduced in preparation for transplant by adding opioid-sparing multimodal medication and his pain intensity decreased.

Patients who are not identified prior to surgery by screening in the preadmission clinic or by their surgical team can be referred to the TPS after surgery by the Acute Pain Service (APS) or by their surgical team. The APS refers patients to TPS if they have intense or prolonged postsurgical pain, high opioid use, notable emotional distress, or the need for ongoing expert pain management consultation and care (see Table 2

Table 2 Transitional Pain Service (TPS) referral criteria

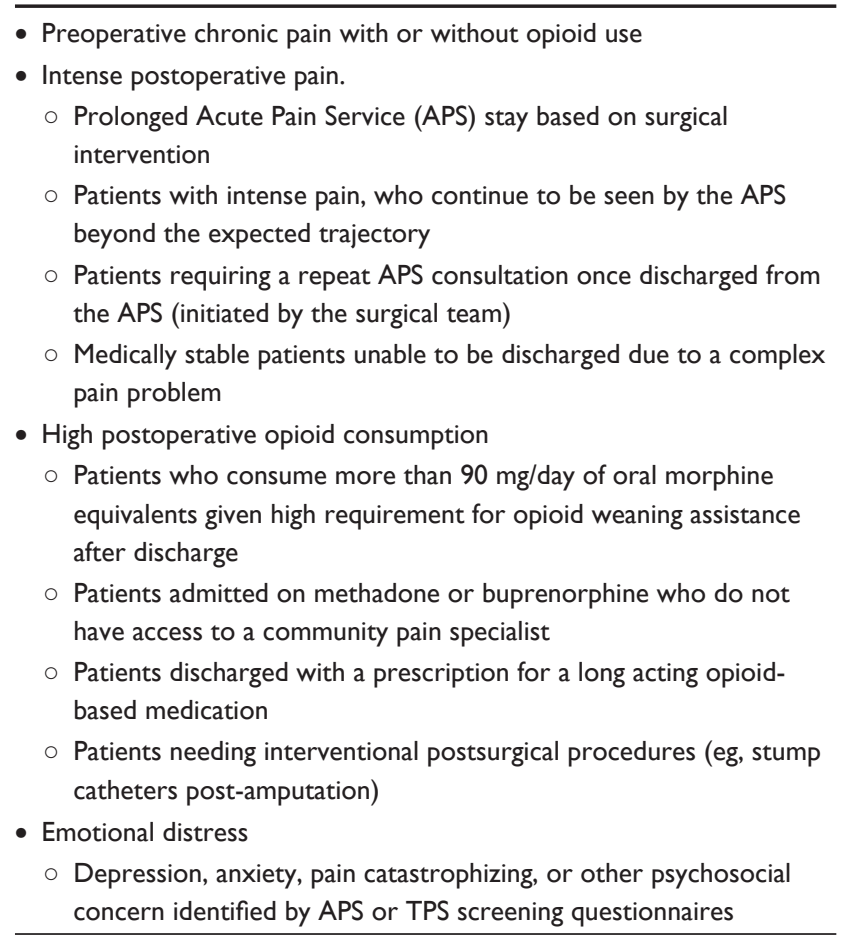

for further details). TPS nurse practitioners begin in-hospital optimization of multimodal analgesia and enhanced teaching for the patient and their family. Patient education may include a review of the analgesics, guidance on better utilization of these analgesics and management of side effects, as well the importance of preventive analgesia in order to reduce pain upon movement and allow patients to participate more effectively in postoperative rehabilitation regimens. Next, one of the TPS pain physicians reviews the patient's chart, assesses the patient (both in person and through a standardized selfreport assessment battery), and develops a multidisciplinary pain plan tailored to the patient's needs. This pain plan may include a referral to a TPS psychologist or physiotherapist, as appropriate, who then begins a personalized intervention while the patient is in hospital. Patients are followed by TPS with continued optimization of analgesic medication and involvement of the multidisciplinary team until hospital discharge. A key goal of this intensive team treatment is to reduce pain and distress as well as delayed discharge due to uncontrolled pain.

\section{Postoperative period}

Once patients are medically fit for discharge, they are booked for follow-up appointments at the TPS outpatient clinic, also located at TGH. Patients receive a follow-up telephone call from the TPS team coordinator within 3 days of hospital discharge. In clinic, follow-up visits generally occur 2 to 3 weeks after discharge, but can take place within days for patients who need urgent care.

At the initial visit to the outpatient TPS clinic after surgery, patient progress is assessed and a detailed discussion is had with the patient (and the patient's family, if present) regarding the pain treatment plan and the process of weaning from opioid medications. The patient is assessed for opioid addiction risk and an opioid agreement contract is signed prior to opioid prescribing. The clinical psychologist is involved with patients who are high-dose opioid users, who have a history of chronic pain or mental health problems, and/or those who report significant current distress and pain (assessed from a standardized set of psychological tools used at intake). Patients are also offered physiotherapy and/ or acupuncture to help restore function and relieve pain. The primary care physicians and surgeons receive a summary of all clinic visits. Patients are assessed once every 2 to 3 weeks and their opioid medications and other analgesics are adjusted until they are at a safe level, their pain is under control, and their daily function approaches their baseline (presurgical) level. The TPS aims to transition patients back 
to their primary care physicians within 6 weeks to 6 months of hospital discharge (ie, after 3-6 visits).

\section{The role of the psychological team within the TPS}

Psychological intervention has a critical, widely established role in the effective multidisciplinary treatment of chronic pain. ${ }^{47}$ In contrast, psychological intervention has rarely been central in the management of postsurgical pain, despite consistent findings that psychological factors such as pain catastrophizing, depression, anxiety, and posttraumatic symptoms are predictive of CPSP outcomes (such as pain intensity, pain-related disability, and opioid use). ${ }^{4,48}$ There is a growing call for integration of psychological services from the earliest time point, rather than waiting for CPSP to be entrenched before such services are offered. ${ }^{49,50}$

\section{Psychological assessment}

The TPS is guided by our awareness of the psychological predictors of CPSP from our earliest contact with each patient. Upon referral to the service (prior to surgery or within days after surgery), patients complete validated self-report measures that assess psychological risk factors (such as pain catastrophizing, depression, and anxiety). In addition, patients undergo a brief assessment interview by a clinical psychologist. The goal of the assessment interview is twofold. First, for patients who are identified as distressed by self-report measures or by the APS, the interview gathers information on the nature of the distress (eg, depression, anxiety, PTSD, limited pain coping repertoire, stressful life circumstances) and identifies early targets for treatment. Secondly, the interview serves to screen for risk factors for opioid misuse. To this end, a brief history is taken of the patient's presurgical functioning in relationships and education/employment, prior history of substance use and misuse, and mental health issues. Psychological risk factors for opioid misuse or difficult postsurgical recovery are communicated to the TPS team.

\section{Psychological intervention}

The goals of psychological intervention within the TPS are to 1) assist patients in the development of personalized pain management plans, 2) address distress and associated mental health issues that have the potential to amplify pain and increase opioid use, 3) support opioid weaning with behavioral pain management skills, and 4) reduce painrelated disability for patients with persistent pain. These key areas must be covered in a brief behavioral intervention that is acceptable to medical patients who are not seeking weekly psychotherapy or other such traditional psychological services.

Our primary modality of psychological intervention is a brief form of Acceptance and Commitment Therapy ${ }^{51}$ (ACT) called the ACT Matrix..$^{52} \mathrm{ACT}$ is a type of cognitive behavioral therapy that incorporates mindfulness, acceptance, and an emphasis on behavioral choices based on personal values. ${ }^{53}$ ACT research on chronic pain has gained momentum over the past 15 years $^{54}$ and now ACT has been rated as having strong research support for the treatment of chronic pain, according to the American Psychological Association, Division $12 .{ }^{55}$ In addition, a growing body of research supports the use of brief ACT workshops for medical patients, including patients with pain conditions such as migraine. ${ }^{56}$ Indeed, medical patients who would not consider psychological treatment - even though they do have comorbid depression, for example - have reported that 1-day ACT workshops are acceptable and helpful to them. ${ }^{56}$

We have adapted our brief ACT protocol into a presurgical workshop delivered in a group format, encompassing both behavioral intervention and pain psychoeducation. We can also provide the intervention to patients on a one-on-one basis, most commonly in a three-session protocol delivered after surgery. The psychological intervention covers many key areas, including identifying personal functioning goals, observing and describing pain and the thoughts and feelings that come with pain, identifying avoidance behaviors and analyzing when they exacerbate pain, distress, and dysfunction, and noticing the impact on pain of engaging in valued activities in a paced manner. A strength of this protocol is that it can be applied transdiagnostically to treat acute and/or chronic pain, depression, anxiety, PTSD, substance misuse, and personality disorders. ${ }^{52}$ Our goal is to test our psychological intervention in a randomized controlled trial to better understand its impact, both short term and long term, on pain intensity, amount of opioid used, mood, and pain disability.

\section{Moving forward: future developments for the TPS}

Given the successful implementation of the TPS in the past year (since 2014), we have begun to expand the program in several ways.

1. We are now accepting referrals for outpatients with moderate to severe postsurgical pain who underwent surgery at other hospitals.

2. We have reached out to family physicians in the community to afford their patients an expedited assessment and intervention process if the patient is within 6 months of the surgical intervention. 
3. We will be expanding the TPS to include patients undergoing orthopedic surgical procedures including total knee and total hip arthroplasties.

4. Based on our research in children and adolescents undergoing major surgery, ${ }^{17,19,57}$ we have identified the transition from adolescence to young adulthood as another significant gap in transitional pain care and plan to develop a specialized arm of the TPS to manage these patients.

5. To enhance the provision of care within the TPS, we are designing physical fitness programs to prehabilitate and rehabilitate participants who are known to improve physical functioning and psychological resilience including yoga and mindfulness practices. ${ }^{58}$

6. We have identified as a priority the need to implement a centralized pharmacy tracking system to monitor opioid prescriptions and prevent double doctoring.

7. To leverage e-health and mobile technology as a way of engaging TPS patients once they are discharged and as a way of improving the assessment and management of CPSP. Beyond complementing the existing TPS program, such technology may improve the accuracy and frequency of patient-reported pain outcomes, enable remote monitoring, provide exception-based alerts, and be a significant part of the equation for predictive analytics.

\section{Conclusion}

Taken together, the current TPS and planned expansions are designed to address the historical gaps in pain management for postsurgical patients. Our goal is to transform the management of pain in postsurgical patients by providing seamless care beginning preoperatively, continuing throughout the hospital stay and after patients return home post-hospital discharge. Finally, important next steps are to determine the efficacy of the TPS in preventing CPSP and to evaluate the extent to which the TPS reduces hospital stay, hospital readmission rates, and overall costs to the health care system.

\section{Acknowledgments}

Joel Katz is supported by Canadian Institutes of Health Research Canada Research Chair in Health Psychology at York University. Hance Clarke is supported by a Merit Award from the Department of Anesthesia, University of Toronto and received funding from the Ontario Ministry of Health and Long Term Care, Medically Complex Patients Demonstration Project Program for a project entitled "The Transitional Pain Service Demonstration Project”.

\section{Disclosure}

The authors report no conflicts of interest in this work.

\section{References}

1. Wall PD, Jones M. Defeating Pain: The War Against a Silent Epidemic. New York, NY: Plenum Press; 1991.

2. Gaskin DJ, Richard P. The economic costs of pain in the United States. J Pain. 2012;13:715-724

3. Parsons B, Schaefer C, Mann R, et al. Economic and humanistic burden of post-trauma and post-surgical neuropathic pain among adults in the United States. J Pain Res. 2013;6:459-469.

4. Katz J, Seltzer Z. Transition from acute to chronic postsurgical pain: risk factors and protective factors. Expert Rev Neurother. 2009;9(5): 723-744.

5. Kehlet H, Jensen TS, Woolf CJ. Persistent postsurgical pain: risk factors and prevention. Lancet. 2006;367(9522):1618-1625.

6. Weiser TG, Regenbogen SE, Thompson KD, et al. An estimation of the global volume of surgery: a modelling strategy based on available data. Lancet. 2008;372(9633):139-144.

7. VanDenKerkhof EG, Hopman WM, Reitsma ML, et al. Chronic pain, healthcare utilization, and quality of life following gastrointestinal surgery. Can J Anaesth. 2012;59(7):670-680.

8. Clarke H, Bonin RP, Orser BA, Englesakis M, Wijeysundera DN, Katz J. The prevention of chronic postsurgical pain using gabapentin and pregabalin: a combined systematic review and meta-analysis. Anesth Analg. 2012;115(2):428-442.

9. Katz J, Clarke H, Seltzer Z. Review article: preventive analgesia: quo vadimus? Anesth Analg. 2011;113(5):1242-1253.

10. Clarke H, Poon M, Weinrib A, Katznelson R, Wentlandt K, Katz J. Preventive analgesia and novel strategies for the prevention of chronic post-surgical pain. Drugs. 2015;75(4):339-351.

11. Huang A, Katz J, Clarke H. Ensuring safe prescribing of controlled substances for pain following surgery by developing a transitional pain service. Pain Manag. 2015;5(2):97-105.

12. Burns LC, Ritvo SE, Ferguson MK, Clarke H, Seltzer Z, Katz J. Pain catastrophizing as a risk factor for chronic pain after total knee arthroplasty: a systematic review. J Pain Research. 2015;15:21-32.

13. Cohen L, Fouladi RT, Katz J. Preoperative coping strategies and distress predict postoperative pain and morphine consumption in women undergoing abdominal gynecologic surgery. J Psychosom Res. 2005;58(2):201-209.

14. Holtzman S, Clarke HA, McCluskey SA, Turcotte K, Grant D, Katz J. Acute and chronic postsurgical pain after living liver donation: incidence and predictors. Liver Transpl. 2014;20(11):1336-1346.

15. Katz J, Asmundson GJ, McRae K, Halket E. Emotional numbing and pain intensity predict the development of pain disability up to one year after lateral thoracotomy. Eur J Pain. 2009;13(8):870-878.

16. Katz J, Jackson M, Kavanagh BP, Sandler AN. Acute pain after thoracic surgery predicts long-term post-thoracotomy pain. Clin J Pain. 1996;12(1):50-55.

17. Pagé MG, Campbell F, Isaac L, Stinson J, Katz J. Parental risk factors for the development of pediatric acute and chronic postsurgical pain: a longitudinal study. J Pain Res. 2013;6:727-741.

18. Pagé MG, Katz J, Romero Escobar M, et al. Distinguishing problematic from non-problematic post-surgical pain: a pain trajectory analysis following total knee arthroplasty. Pain. March 2015;156(3):460-468.

19. Pagé MG, Stinson J, Campbell F, Isaac L, Katz J. Identification of painrelated psychological risk factors for the development and maintenance of pediatric chronic postsurgical pain. J Pain Res. 2013;6:167-180.

20. Hoofwijk DM, Fiddelers AA, Peters ML, et al. Prevalence and predictive factors of chronic postsurgical pain and poor global recovery one year after outpatient surgery. Clin J Pain. Epub Jan 62015.

21. Miaskowski C, Paul SM, Cooper B, et al. Identification of patient subgroups and risk factors for persistent arm/shoulder pain following breast cancer surgery. Eur J Oncol Nurs. 2014;18(3):242-253. 
22. Bruce J, Thornton AJ, Powell R, et al. Psychological, surgical, and sociodemographic predictors of pain outcomes after breast cancer surgery: a population-based cohort study. Pain. 2014;155(2):232-243.

23. Masselin-Dubois A, Attal N, Fletcher D, et al. Are psychological predictors of chronic postsurgical pain dependent on the surgical model? A comparison of total knee arthroplasty and breast surgery for cancer. J Pain. 2013;14(8):854-864.

24. Hanley MA, Jensen MP, Smith DG, Ehde DM, Edwards WT, Robinson LR. Preamputation pain and acute pain predict chronic pain after lower extremity amputation. J Pain. 2007;8(2):102-109.

25. Brandsborg B, Nikolajsen L, Hansen CT, Kehlet H, Jensen TS. Risk factors for chronic pain after hysterectomy: a nationwide questionnaire and database study. Anesthesiology 2007;106(5):1003-1012.

26. VanDenKerkhof EG, Hopman WM, Goldstein DH, et al. Impact of perioperative pain intensity, pain qualities, and opioid use on chronic pain after surgery: a prospective cohort study. Reg Anesth Pain Med. 2012;37(1):19-27.

27. Kleiman V, Clarke H, Katz J. Sensitivity to pain traumatization: a higherorder factor underlying pain-related anxiety, pain catastrophizing and anxiety sensitivity among patients scheduled for major surgery. Pain Res Manag. 2011;16(3):169-177.

28. Attal N, Masselin-Dubois A, Martinez V, et al. Does cognitive functioning predict chronic pain? Results from a prospective surgical cohort. Brain. 2014;137(Pt 3):904-917.

29. Archer KR, Seebach CL, Mathis SL, Riley LH 3rd, Wegener ST. Early postoperative fear of movement predicts pain, disability, and physical health six months after spinal surgery for degenerative conditions. Spine J. 2014;14(5):759-767

30. Belfer I, Schreiber KL, Shaffer JR, et al. Persistent postmastectomy pain in breast cancer survivors: analysis of clinical, demographic, and psychosocial factors. J Pain. 2013;14(10):1185-1195.

31. Katz J, Poleshuck EL, Andrus CH, et al. Risk factors for acute pain and its persistence following breast cancer surgery. Pain. 2005;119(1-3): $16-25$.

32. Theunissen M, Peters ML, Bruce J, Gramke HF, Marcus MA. Preoperative anxiety and catastrophizing: a systematic review and meta-analysis of the association with chronic postsurgical pain. Clin J Pain. 2012;28(9):819-841.

33. Khan RS, Ahmed K, Blakeway E, et al. Catastrophizing: a predictive factor for postoperative pain. Am J Surg. 2011;201(1):122-131.

34. Ip HY, Abrishami A, Peng PW, Wong J, Chung F. Predictors of postoperative pain and analgesic consumption: a qualitative systematic review. Anesthesiology. 2009;111(3):657-677.

35. Katz J, Buis T, Cohen L. Locked out and still knocking: predictors of excessive demands for postoperative intravenous patient-controlled analgesia. Can J Anaesth. 2008;55(2):88-99.

36. Baratta JL, Schwenk ES, Viscusi ER. Clinical consequences of inadequate pain relief: barriers to optimal pain management. Plast Reconstr Surg. 2014;134(4 Suppl 2):15S-21S.

37. Gurusamy KS, Vaughan J, Toon CD, Davidson BR. Pharmacological interventions for prevention or treatment of postoperative pain in people undergoing laparoscopic cholecystectomy. Cochrane Database Syst Rev. 2014;3:CD008261.

38. Jones NL, Edmonds L, Ghosh S, Klein AA. A review of enhanced recovery for thoracic anaesthesia and surgery. Anaesthesia. 2013;68(2): 179-189.

39. Joshi GP, Ogunnaike BO. Consequences of inadequate postoperative pain relief and chronic persistent postoperative pain. Anesthesiol Clin North America. 2005;23(1):21-36.

40. Robinson KP, Wagstaff KJ, Sanghera S, Kerry RM. Postoperative pain following primary lower limb arthroplasty and enhanced recovery pathway. Ann R Coll Surg Engl. 2014;96(4):302-306.
41. Morasco BJ, Turk DC, Donovan DM, Dobscha SK. Risk for prescription opioid misuse among patients with a history of substance use disorder. Drug Alcohol Depend. 2013;127(1-3):193-199.

42. Jamison RN, Link CL, Marceau LD. Do pain patients at high risk for substance misuse experience more pain? A longitudinal outcomes study. Pain Med. 2009;10(6):1084-1094.

43. Grattan A, Sullivan MD, Saunders KW, Campbell CI, Von Korff MR. Depression and prescription opioid misuse among chronic opioid therapy recipients with no history of substance abuse. Ann Fam Med. 2012;10(4):304-311.

44. Martel MO, Wasan AD, Jamison RN, Edwards RR. Catastrophic thinking and increased risk for prescription opioid misuse in patients with chronic pain. Drug Alcohol Depend. 2013;132(1-2): 335-341.

45. Clarke H, Soneji N, Ko DT, Yun L, Wijeysundera DN. Rates and risk factors for prolonged opioid use after major surgery: population based cohort study. Br Med J. 2014;348:g1251.

46. Shipton EA. The transition of acute postoperative pain to chronic pain: Part 1 - Risk factors for the development of postoperative acute persistent pain. Trends Anaesth Crit Care. 2014;4(2):67-70.

47. Flor H, Fydrich T, Turk DC. Efficacy of multidisciplinary pain treatment centers: a meta-analytic review. Pain. 1992;49(2):221-230.

48. Shipton EA. The transition of acute postoperative pain to chronic pain: Part 1 - Risk factors for the development of postoperative acute persistent pain. Trends Anaesth Crit Care. 2014;4(2): $67-70$.

49. Shipton EA. The transition of acute postoperative pain to chronic pain: Part 2 - Limiting the transition. Trends Anaesth Crit Care. 2014;4(2-3):71-75.

50. Wicksell RK, Olsson GL. Predicting and preventing chronic postsurgical pain and disability. Anesthesiology 2010;113(6):1260-1261.

51. Hayes SC, Strosahl KD, Wilson KG. Acceptance and Commitment Therapy: The process and Practice of Mindful Change (Second Edition). New York, NY: Guilford Press; 2011.

52. Polk K, Schoendorff B, editors. ACT Matrix: A New Approach to Building Psychological Flexibility across Settings and Populations. Oakland, CA: New Harbinger Publications, Inc.; 2014.

53. Hayes SC, Villatte M, Levin M, Hildebrandt M. Open, aware, and active: contextual approaches as an emerging trend in the behavioral and cognitive therapies. Annu Rev Clin Psychol. 2011;7:141-168.

54. Scott W, McCracken LM. Psychological flexibility, acceptance and commitment therapy, and chronic pain. Curr Opin Psychol. 2015;2:91-96.

55. Acceptance and Commitment Therapy EST Status for Chronic or Persistent Pain: Strong Research Support. Society of Clinical Psychology (Division 12), American Psychological Association web site. http://www.div12.org/psychological-treatments/disorders/chronic-orpersistent-pain/acceptance-and-commitment-therapy-for-chronic-pain/ Published 2013. Accessed June 1, 2015

56. Dindo L. One-day acceptance and commitment training workshops in medical populations. Curr Opin Psychol. 2015;2:38-42.

57. Pagé MG, Stinson J, Campbell F, Isaac L, Katz J. Pain-related psychological correlates of pediatric acute post-surgical pain. J Pain Res. 2012;5:547-558.

58. Santa Mina D, Clarke H, Ritvo P, et al. Effect of total-body prehabilitation on postoperative outcomes: a systematic review and meta-analysis Physiotherapy 2014;100(3):196-207. 
Journal of Pain Research

\section{Dovepress}

\section{Publish your work in this journal}

The Journal of Pain Research is an international, peer-reviewed, open access, online journal that welcomes laboratory and clinical findings in the fields of pain research and the prevention and management of pain. Original research, reviews, symposium reports, hypothesis formation and commentaries are all considered for publication.

The manuscript management system is completely online and includes a very quick and fair peer-review system, which is all easy to use. Visit http://www.dovepress.com/testimonials.php to read real quotes from published authors.

Submit your manuscript here: http://www.dovepress.com/journal-of-pain-research-journal 